\title{
JUVENTUD Y LECTURA: UNA INVESTIGACIÓN SOBRE ADOLESCENTES EN BARCELONA ${ }^{1}$
}

Nombre: Isabel Travancas.

Afiliación: Escola de Comunicação - UFRJ.

Dirección electrónica: isabeltravancas@yahoo.com

Barcelona es archivo de la cortesía, albergue de los extranjeros, hospital de los pobres, patria de los valientes, venganza de los ofendidos y correspondencia grata de firmes amistades, y en sitio y en belleza, única.

Miguel de Cervantes en Don Quijote de La Mancha.

Recuperação da adolescência

é sempre mais difícil ancorar um navio no espaço.

Ana Cristina César

\section{Resumen}

El objetivo de este artículo es dar a conocer las primeras conclusiones referentes a una investigación hecha con adolescentes de Barcelona sobre su relación con la lectura, que se llevó a cabo en 2013 en dicha ciudad. El estudio de campo tuvo inicio con una presentación de datos acerca de la lectura en España y se concentró en cuatro escuelas públicas pertenecientes a cuatro regiones distintas: Ciutat Vella (Ciudad Vieja): Raval y Barceloneta, Sarrià -Sant Gervasi- Gràcia y Zona Franca. En cada escuela se aplicaron, en una primera etapa, cuestionarios que trataban de la lectura y que sumaron un total de 248 . Ya en la segunda etapa se realizaron entrevistas grupales a cerca de 45 jóvenes, y en la etapa final, se realizaron también algunas entrevistas individuales. La investigación me hizo ver que la lectura forma parte de la vida cotidiana de esos jóvenes de diferentes maneras: por intermedio de la escuela y de la obligación de leer, o como fruto de un hábito de lectura ya adquirido y que se relaciona con el placer. Se hizo evidente que los padres que leen ejercieron influencia en la formación de lectores. Además, otro elemento importante en el contexto español fue la dimensión simbólica y cultural de las bibliotecas de barrio, las cuales son bastante frecuentadas por los jóvenes en cuestión. Finalmente, pude observar que los jóvenes precisan mucho de un espacio para expresarse libremente y que la escuela realmente es vista como un lugar de obligación en el que la lectura no se asocia al placer.

\footnotetext{
${ }^{1}$ Esta investigación, la cual fue posible gracias al auxilio de una Beca Postdoctoral Senior de la CAPES, en 2013, fue realizada en el GRAFO -Grupo de Investigación en Antropología Fundamental y Orientada del Departamento de Antropología de la Universidad Autónoma de Barcelona, bajo la supervisión de la Profa. Dra. Pepi Soto.
} 
Número 3, mayo 2014. No 03/05. ISSN: 2014-5993

Este trabajo forma parte de una investigación más amplia que abarca un trabajo comparativo con adolescentes de Río de Janeiro.

\begin{abstract}
This paper presents the initial findings of a 2013 survey of adolescents in Barcelona regarding their relations with reading. It begins with a presentation of data regarding reading in Spain and then proceeds to data collected in the field. This data was gathered at four public schools in four distinct regions: Ciutat Vella (Ciudad Vieja), Raval and Barceloneta, Sarrià - Sant Gervasi - Gràcia and Zona Franca. At each school, questionnaires regarding reading were initially applied and 248 of these were collected. During the second stage of the research, interviews were conducted in groups of about 45 young people. Finally, individual interviews were carried out. I discovered that reading is part of the daily life of young people in different ways. It enters into the lives of youth either through the school and their obligation to read, or through already acquired reading habits which are related to pleasure. It was clear that readers' parents influence the formation of readers. Another important element in the Spanish context was the symbolic and cultural dimensions of the neighborhood libraries frequented by the very young. Finally, I noticed that many youths need a space to express themselves freely, as the school is seen as a place of obligation where reading is not associated with pleasure. This research is part of a broader, comparative study of adolescents in Rio de Janeiro.
\end{abstract}

\title{
Introducción.
}

Muchas veces el comienzo de una investigación es nebuloso. ¿Por qué elegimos determinados temas? ¿Cómo llegamos a ellos y cuáles son las relaciones subjetivas que nos llevaron a decidir investigarlos? El punto de partida de este estudio fueron dos ocupaciones fundamentales en mi vida: la de madre y la de profesora universitaria. Soy madre de una adolescente brasileña que lee bastante, cuyos amigos son también lectores y fans de series best sellers como Harry Potter y Crepúsculo. Y me preguntaba por qué se afirma de manera tan categórica que los jóvenes no leen, en particular, los adolescentes. En segundo lugar, como profesora en la Escuela de Comunicación de la Universidad Federal de Rio de Janeiro (UFRJ) -la mayor y la más antigua universidad pública de Brasil, que además cuenta con una demanda muy alta en términos de vacante/candidato- me cuestionaba por qué mis alumnos, muchos de ellos grandes lectores, de modo general desconocían y sentían rechazo por la literatura brasileña. Esos fueron los dos puntos de partida de la presente investigación.

Por otro lado, mucho se afirma que los jóvenes de hoy no leen, que solo se conectan a la computadora y al celular y que los libros están perdiendo espacio entre ellos en diversos países, no solamente en Brasil, un país sin tradición lectora. Para intentar evaluar en qué medida esa visión era pertinente, decidí, mediante el análisis de números, tiraje y títulos de éxito para los jóvenes, acercarme a ellos y escucharlos. 
Número 3, mayo 2014. No 03/05. ISSN: 2014-5993

¿Pero qué jóvenes y jóvenes de dónde? El público elegido para la investigación fueron los adolescentes de Río de Janeiro (Brasil) y de Barcelona (España), y el objetivo consistió en realizar un estudio comparativo sobre la experiencia de la lectura en estos dos universos tan distintos. En el presente artículo voy a detenerme en la parte de la investigación que fue llevada a cabo en Barcelona en 2013.

Procuré utilizar diferentes metodologías y reunir datos de estudiantes de cuatro escuelas de Barcelona. Los jóvenes tenían de 13 a 17 años y cursaban ESO o Bachillerato. En un primer momento apliqué cuestionarios con preguntas abiertas y cerradas, luego, en un segundo momento, realicé entrevistas grupales con los estudiantes que tenían interés y disponibilidad para participar de las mismas.

\section{Dos mundos.}

La entrada en campo comenzó con mi llegada a Barcelona a fines de diciembre de 2013 y con la acogida recibida en GRAFO -Grupo de Investigación en Antropología Fondamental y Orientada- del Departamento de Antropología de la Universidad Autónoma de Barcelona. Al fin de cuentas, se trataba de una antropóloga brasileña que llegaba para estudiar una sociedad y un grupo diferente del suyo. Una vez adaptada a la ciudad, la cual me recibió muy bien, e integrada ya al campus de la universidad y al grupo de profesores, decidí pensar con qué escuelas trabajaría y de qué modo las iba a seleccionar. Por tratarse de una investigación comparativa con una primera etapa ya concluida en 2012, en Río de Janeiro, decidí hacer algo siguiendo los mismos procedimientos.

A simple vista puede parecer muy extraño comparar jóvenes de ciudades tan diferentes, con características culturales diversas, con hábitos de lectura distintos, por mencionar algunos puntos de contraste. Sin embargo, creo que Barcelona y Río de Janeiro también presentan puntos en común, y fueron precisamente esos elementos comunes los que me estimularon a sugerir esta investigación. Las dos ciudades, dentro de sus países, son muy importantes, aun sin ser capitales. Tienen una historia fuerte, son ciudades de playa, cosmopolitas, que reciben mucha gente de afuera. En el caso de Barcelona, recibe gente de otras nacionalidades; en el caso de Río, de otros estados del país. Además, son ciudades con un mercado editorial fuerte y con una vida cultural intensa.

Una de las grandes diferencias entre las dos -diferencia que dice más de los países que de las ciudades- es el tema de la lengua. Brasil es un país que cuenta con una única lengua oficial, el portugués, y que aun teniendo dimensiones continentales, no presenta fuertes disputas en ese terreno. Las lenguas indígenas que sobrevivieron existen gracias a los movimientos de resistencia y solo circulan dentro del universo indígena. El catalán es una 
Número 3, mayo 2014. No 03/05. ISSN: 2014-5993

lengua fuerte que se halla presente no solo en Barcelona, sino también en toda Cataluña. Es la lengua que se usa en la calle y en las escuelas, a pesar de la presión en contrario del Gobierno español. Las cuestiones en torno al catalán aparecen también en la relación de los alumnos con la lectura y con los libros leídos, así como en la relación con los padres, muchos de ellos extranjeros.

Diferencias. En términos de tamaño y población la diferencia es enorme. España cuenta con un área de 500 mil $\mathrm{Km}^{2}$ y con una población de más de 47 millones de habitantes. De esos, cerca de 9 millones son jóvenes con menos de 20 años. Brasil, en cambio, cuenta con un área de más de 190 millones de $\mathrm{Km}^{2}$ y con una población de casi 200 millones de habitantes. De ese total, 35 millones son jóvenes entre 15 y 24 años. Es decir, la cantidad de jóvenes en Brasil equivale a la población total de un país. En términos de ciudades, Barcelona y Río de Janeiro, las diferencias continúan. La ciudad brasileña cuenta con un área de más de 1.200 $\mathrm{Km}^{2}$ y con una población de más de 6 millones y medio de habitantes y más de 460 mil jóvenes. Ya Barcelona cuenta con un área de 100,9 $\mathrm{Km}^{2}$ y con una población de cerca de 1 millón 600 mil habitantes, de los cuales 126 mil son jóvenes entre 10 y 19 años.

Las investigaciones en torno a la lectura en los dos países también apuntan diferencias muy grandes. La definición de lector que fue usada en las dos investigaciones es la misma: alguien que leyó por lo menos un libro entero en los últimos tres meses. En la tercera edición de la investigación Retratos da Leitura no Brasil, llevada a cabo en 2012, la población con más de 5 años de edad se divide en $50 \%$ lectores y $50 \%$ no lectores. El promedio de libros que se lee por habitante, al año, es de cuatro. En la investigación Hábitos de Lectura 2012 que se realizó en España, el 92\% de toda la población con más de 14 años es lectora. Hay una diferencia de criterio entre las dos en lo concerniente al universo de la investigación. Una toma en cuenta a quien tiene más de cinco años y la otra a quien tiene más de 14 . EI promedio de libros que se lee por habitante en España, al año, es de 11,1.

En España la presencia de las bibliotecas está muy diseminada y las mismas son frecuentadas por un $30 \%$ de la población que lee principalmente en casa $(91,4 \%)$. A este porcentaje le siguen un $13 \%$ de los que leen en el transporte; un 9,6\%, al aire libre; un $8,9 \%$, en el trabajo; un $5,6 \%$, en cafés; un $3,4 \%$, en la biblioteca; un $3 \%$, en la escuela y un $2,1 \%$, en otros lugares no especificados.

En Brasil, apenas un 7\% de la población usa con frecuencia la biblioteca; un 17\% la usa de vez en cuando y un $75 \%$ no la usa. Por sí solos, estos datos ya demuestran la relación de distanciamiento que existe entre los brasileños y las bibliotecas. En relación a los lugares en los que acostumbran a leer, la casa aparece en primer lugar con un $93 \%$, seguida del aula con un $33 \%$, de las bibliotecas con un $12 \%$, del trabajo con un $13 \%$, del transporte con un 
Número 3, mayo 2014. No 03/05. ISSN: 2014-5993

$6 \%$, de la casa de amigos y parientes con un $4 \%$, de consultorios o salones de belleza con un $3 \%$, de parques y plazas con un $2 \%$ y de otros lugares no especificados con un $8 \%$.

Otro elemento que se halla presente en la investigación de los dos países y que considero relevante para que se piense el lugar que ocupa la lectura en el imaginario de la población, y el significado simbólico del libro, es la idea del libro dado como regalo. En el caso de la población brasileña, esto ocurrió en apenas un $2 \%$ de casos; algunas veces en un $11 \%$ y un $87 \%$ nunca recibió un libro de regalo. Es decir, no se considera al libro como un objeto legítimo ni se lo valora como un regalo que puede ser dado en un cumpleaños o en Navidad, por ejemplo. En la investigación sobre la lectura en España no hay una pregunta específica sobre el libro dado como regalo. La idea del regalo aparece únicamente en el ítem "Razones de compra" de un libro. Las respuestas revelan que el último libro comprado fue, en un $15 \%$, para dar de regalo; en un $72,3 \%$, para entretenerse y divertirse y en un $7,3 \%$, por motivos de estudio.

Junto con todos estos datos, me viene a la cabeza una campaña que vi en la TVE Canal 2, en abril de 2013, cuyo slogan decía "Somos lo que leemos". Las imágenes mostraban a un hombre leyendo a Cervantes, luego a una mujer leyendo Cien años de soledad y terminaba con "Pasión por leer". Fue una campaña nacional que pasaron por la televisión para estimular la lectura, consistente en crear una asociación entre nuestra identidad y lo que leemos.

Hasta aquí, algunos datos de las dos investigaciones nacionales, las cuales creo que ayudan a comprender un poco el escenario de la lectura en Brasil y en España, en este comienzo del siglo XXI.

\section{La entrada en el campo.}

La investigación se centró fundamentalmente en las escuelas. Escuelas de enseñanza media con jóvenes entre 13 y 17 años, universo de la investigación. La misma fue realizada en cuatro institutos de Barcelona llamados mixtos, lo que significa que son al mismo tiempo públicos y privados. En España son raros los institutos denominados "concertados", que son aquellos exclusivamente públicos o exclusivamente privados.

¿De qué manera elegir las escuelas y cómo llegar a ellas? Mi referencia era la investigación realizada en Río de Janeiro en 2012, para la que fui a cinco escuelas -tres públicas y dos privadas- de barrios de la zona sur (región económicamente más favorecida), del centro y de la periferia de la ciudad. El perfil socioeconómico y cultural de los alumnos, en todas esas escuelas, era muy diferente. Mi entrada a las escuelas fue relativamente fácil, bastando, en general, un contacto personal con algún profesor o coordinador. Prácticamente no hubo 
Número 3, mayo 2014. No 03/05. ISSN: 2014-5993

ninguna dificultad de contacto, ingreso o incluso de agenda para que fuera posible $\mathrm{mi}$ entrada a la escuela, la aplicación de los cuestionarios y la realización de las entrevistas. Hubo solamente una escuela que solicitó una carta más formal en la que se detallaran los objetivos de la investigación, el tipo de vínculo que mantenía con la universidad y que además solicitó ver el cuestionario que los alumnos debían responder. Fue esa escuela, también, la que pidió no ser identificada en la investigación y la que prohibió que los alumnos informaran sus e-mails, nombres completos o teléfonos en el cuestionario. Finalmente, exigieron que las entrevistas fueran realizadas dentro de la escuela en el horario de clase. Esto acabó ocurriendo en casi todas las escuelas, pero por razones de logística y de agenda de los estudiantes.

En Barcelona el ingreso a mi campo de estudio fue muy distinto. Más complejo y más lento. En un primer momento intenté comprender el contexto de Barcelona, en donde, felizmente, no existe la misma desigualdad social de Río de Janeiro, por lo que el contraste entre las escuelas y sus estudiantes es menor. A partir de la orientación de mi supervisora, elegí seis escuelas y empecé a hacer los contactos. Mi supervisora ya conocía una de esas escuelas, por lo que me la presentó y me preguntó sobre la posibilidad de ir allá para hacer la investigación. Agendamos un encuentro en febrero pensando en comenzar a aplicar los cuestionarios en marzo. La coordinadora pedagógica me recibió muy bien, hizo varias observaciones, analizó el cuestionario y estudió en el calendario los días y horarios en que podría ir a la escuela. Sin embargo, luego me preguntó qué le daría a cambio a la escuela por la participación en la investigación. La pregunta me tomó de sorpresa ya que en ningún momento, durante todo el proceso de campo en Río de Janeiro, había surgido esa cuestión. Muy por el contrario, se mostraron bastante dispuestos, aun mostrando algunas escuelas más interés que otras. Pero ninguna escuela estableció una condición para que pudiera realizar la investigación. Respondí que presentaría los primeros resultados de la investigación a fines de 2013, cuando estuviera terminada esta etapa, y que me comprometía a enviarle a la escuela una copia del trabajo final. Esto, sin embargo, no fue suficiente. Margarita del Olmo (2010: 80) llama la atención a lo compleja que es la investigación hecha en las escuelas y al rol del antropólogo dentro de ese contexto. En su experiencia de trabajo de campo en "Aulas de enlace" fue presentada como una profesora de apoyo, construyéndose así una relación ambigua en términos de poder. Su presencia dentro de la escuela era un riesgo grande y no podía compensarse con aquello que ella podría "ofrecerles a ellos a cambio". Por lo tanto, me parece evidente que la investigación en las escuelas presenta dificultades y particularidades. La escuela es observada. Creo que el hecho de ser extranjera, en mi caso, facilitó mucho la acogida. Hay algo de "exótico" en eso, en tener una antropóloga brasileña estudiando a los alumnos de la escuela y, en última 
Número 3, mayo 2014. No 03/05. ISSN: 2014-5993

instancia, a la escuela también. También me vino a la mente la frase de Olmo (2010: 78) cuando decía que "los etnógrafos somos investigadores que usamos personas como herramientas". Aun cuando lo hagamos con todo cuidado, sea por respeto a nuestros "nativos", sea por su anonimato, por su libertad de habla y ausencia de juicios de valor, las personas son instrumentos que usamos para entender un tema y un problema.

También me di cuenta de que en las escuelas de Barcelona, a causa de la "crisis", se encuentran en un momento de mucho trabajo, con menos presupuestos, con un equipo menor y con muchos alumnos. Fue por eso que se me ocurrió la idea de ofrecerme para dar una "clase" sobre Brasil. Y la propuesta fue muy bien recibida. Me comprometí, entonces, a darles a los estudiantes, una vez aplicados los cuestionarios y realizadas las entrevistas, una clase sobre mi país. $Y$ también a volver a la escuela al final del año para un encuentro con el equipo de profesores y coordinadores y presentarles los resultados del estudio.

Entré en contacto con las otras escuelas pero hasta el día 23 de abril, Fiesta de Sant Jordi, no había vuelto a la primera escuela ni había obtenido ninguna respuesta de los otros institutos con los que me había contactado por correo electrónico o teléfono. Fue entonces que mi supervisora decidió entrar en contacto con el equipo de la Secretaría de Educación de Barcelona, con el que ya había trabajado años atrás, para explicarles la situación. Hablé con Clara Balaguer del sector de Educación Secundaria, quien se mostró bastante interesada en la investigación, así como en ayudarme. Luego de conversar con las escuelas, ella me pasó los nombres y correos electrónicos necesarios para que pudiera agendar una visita y comenzar el trabajo. Considero este detalle muy interesante en el contexto de la investigación comparativa, ya que tenemos una visión de nosotros mismos, brasileños, y de nuestra sociedad, de ser muy relacionales, en donde las relaciones personales tienen mucho peso, abren puertas, definen trayectorias y también impiden el ingreso a ciertos espacios. Me sorprendí al darme cuenta de que Barcelona no era tan diferente a como la había imaginado. A partir de ese momento, mi entrada a las escuelas fue mucho más fácil: bastó un contacto por correo electrónico el cual, en general, obtuvo una rápida respuesta. También fue más fácil combinar las fechas para mi visita y para la aplicación de los cuestionarios, y definir los cursos en los que serían aplicados. Es decir, la interferencia y el empeño de Clara Balaguer fueron fundamentales para el desarrollo de esta investigación.

\section{Las cuatro escuelas de Barcelona.}

La educación y la escuela en España y en Barcelona pasaron por muchas transformaciones. En la lectura de Un segle d'escola a Barcelona pueden acompañarse esos cambios. Jaume Carbonell Sebarroja (2003: 252) resalta que a comienzos del siglo XX el escenario de la 
Número 3, mayo 2014. No 03/05. ISSN: 2014-5993

educación era precario. "Se trata sin duda de una escuela absolutamente insuficiente, con millares de niños en la calle, y muy deficiente en lo de las condiciones y a la calidad pedagógica se refiere".

La escuela pública laica, como institución fundamental de la nación, está muy ligada a la República y fue recuperada en el período pos-franquista. Las escuelas que componen el universo de esta investigación deben ser pensadas teniéndose en cuenta este contexto.

El Institut d'Educació Josep Serrat i Bonastre, localizado en la zona de Sarrià -Sant GervasiGràcia, funciona donde era la Escuela de Artes y Oficios que fue fundada en 1890. Tiene 310 alumnos en ESO y Bachillerato y un $35 \%$ de ellos es extranjero. Esta fue la primera escuela que visité y su coordinadora, en aquella ocasión, me invitó a presenciar las actividades del día de Sant Jordi. Es una tradición realizar los "Jocs Florals" (Juegos Florales), evento en el que los alumnos escriben y recitan poemas de su autoría o de poetas famosos. Fue encantador poder ver a toda la escuela movilizada para la realización de esta fiesta de rosas y libros que invade a Barcelona de una manera muy especial. ${ }^{2}$

Para esta fecha cada curso de la escuela había preparado algo especial. Los dos cursos de nivel secundario a los que fui habían hecho textos - principalmente poesía- en homenaje al escritor, poeta y novelista catalán Salvador Espriu (1913-1985), en el año de su centenario, el cual fue denominado "Año Espriu". La lectura de los textos ocurrió en la biblioteca, pero antes de comenzar la profesora me presentó a todos como invitada. Otra profesora que estaba presente sacó fotos. Se mostraron amables y sonrientes. Los alumnos leyeron en voz alta con imágenes y música. Los textos eran muy sufridos. Hablaban de la muerte de un abuelo, del suicidio de la madre, de la pérdida de un amor, de la desilusión. Hablaban también de amistad, un vínculo muy importante en la adolescencia. Un alumno dice: "Un amigo es un tesoro que no necesita de mapas". El clima en la biblioteca era bastante tranquilo y silencioso. Eran jóvenes "normales" que me recordaron a los alumnos de la escuela de mi hija en la zona sur de Río de Janeiro. Los alumnos, en su mayoría, eran

\footnotetext{
${ }^{2}$ San Jorge, patrono de Cataluña, siempre fue motivo de fiesta en la región, incluso antes de que se lo asociara con la fiesta del libro. El Día Internacional del Libro fue instituido en Cataluña y se empezó a conmemorar en 1926, el día 05 de abril, fecha del nacimiento del escritor Miguel de Cervantes. En 1930 pasó a conmemorarse el día 23, día de la muerte de ese autor. Ya en 1995 la UNESCO consagró esa fecha como Día Mundial del Libro por ser también el día del fallecimiento de William Shakespeare. La tradición en Barcelona es que los hombres les den rosas a las mujeres y estas un libro a los hombres, en alusión a la leyenda de San Jorge. Este habría matado al dragón que aterrorizaba al pueblo y de su sangre nació una rosa que el caballero dio a la princesa. En esta fecha, la ciudad se llena de puestos de libros y de rosas. Las vidrieras de los negocios, no solo de las librerías, hacen alusión a la fiesta. En las librerías y plazas públicas hay debates con escritores. Es el día con mayor venta de libros, incluso, muchas veces, en comparación con la Navidad. Curiosamente, desde el año 2001 el día 23 de abril también es feriado en Río de Janeiro y, además, San Jorge también es patrono de la ciudad. Una cosa más que une a Barcelona y a Río de Janeiro.
} 
Número 3, mayo 2014. No 03/05. ISSN: 2014-5993

blancos, algunos eran sudamericanos, casi todos de cabello lacio, vistiendo jeans. Algunos vestían bermudas. Las chicas tenían las uñas pintadas de todos los colores. Algunos pocos alumnos eran "mulatos". Presentaron buenos textos y los compañeros parecían interesados en escucharlos. Al final de la presentación hubo palmas y una vez acabado el evento, me dirigí a la sala de los "Cuentacuentos", en donde estaban los alumnos del $4^{\circ}$ año con la profesora que había hecho un trabajo de interpretación de un texto en catalán. Después volví a la biblioteca para otra actividad con textos hechos por los alumnos, pero esta vez en catalán. La profesora de la disciplina me explicó que ellos habían tenido total libertad para elegir los textos, los autores y para elegir hacer el trabajo de forma grupal o individualmente. En algunas presentaciones, un alumno tocó el violín. Al final, todos juntos leyeron el poema "Macedonia Poética" de Joan Papasseit. No era feriado pero había un clima de fiesta y varias chicas habían recibido una rosa de regalo.

Unos días después volví a la primera escuela para la aplicación de los cuestionarios en dos cursos. La puerta de entrada de la escuela estaba cerrada, por lo que tuve que identificarme con el portero. Me quedé en el hall de entrada esperando que la coordinadora me viniera a buscar para llevarme al aula. Ella ya les había comentado a los alumnos sobre mi visita y estos estaban ansioso por conocerme. Entré al aula y la profesora les dijo a los alumnos que yo era una profesora brasileña que estaba haciendo una investigación sobre el tema de la lectura. También les pidió que se comportaran. Les hizo varias recomendaciones, les pidió silencio y yo me inquieté un poco porque esperaba un "clima" más relajado para presentar mi trabajo de investigación. Hablé de mi proyecto, del objetivo, del porqué estaba allí y ellos se mostraron curiosos por el hecho de que yo fuera brasileña. Entregué los cuestionarios y les dije que si tenían alguna duda podían preguntarme. En el cuestionario había varias preguntas sobre el barrio y una en la que se pedía que eligieran dos ítems. En donde se pedía que citaran algún libro, algunas personas no consiguieron recordar ninguno. Les expliqué que después de los cuestionarios iba a hacer entrevistas grupales y que quien quisiese participar debía responder afirmativamente en la última pregunta. Enseguida muchos dijeron que querían participar. Paralelamente, la profesora me comentó sobre algunos alumnos y me sugirió incluir algunos nombres de alumnos que eran muy lectores. Le agradecí por esto pero le subrayé que la investigación era sobre lectura y que también me interesaba oír a los no lectores. Dije además que creía fundamental la participación de estos por su propia voluntad, así como que pudieran hablar con libertad.

De inmediato fui al otro curso, el cual también se mostró bastante interesado, al igual que la profesora. Nuevamente encontré alumnos curiosos, interesados y que querían ser entrevistados. Al final, después de una rápida visita a la sala de los profesores, los acompañé a estos a un café de la esquina para la "merienda". Fue un momento de gran 
Número 3, mayo 2014. No 03/05. ISSN: 2014-5993

privilegio en el que pude oírlos hablar sobre sus dificultades, sobre el perfil de los alumnos, sobre las actividades que realizan. Muchos afirmaron que esa era una "buena" escuela, que la misma tenía "buenos" alumnos y que varios de ellos eran muy lectores.

El Institut d' Educación Secundària Miquel Tarradell queda en Ciutat Vella -Raval- y fue creado en 1996. Funciona en un edificio del período de la República de comienzos del siglo XX. Tiene un total de 450 alumnos de más de 15 nacionalidades. Según la coordinadora, aunque esa mezcla traiga de por sí dificultades, no se vive un clima de conflicto dentro de la institución, sino que, por el contrario, hay bastante cordialidad.

El primer contacto fue por correo electrónico para combinar una visita a la institución y para realizar el envío de los cuestionarios que serían aplicados en los cursos que ellos mismos seleccionarían. La coordinadora estaba interesada en la investigación y estaba dispuesta a ayudarme. Cuando llegué a la escuela, me presentó a los otros profesores, me contó un poco sobre la institución y me dijo que entraría en contacto conmigo cuando los cuestionarios estuvieran respondidos. Le dije que sería bueno que yo misma se los pudiera entregar a los alumnos, incluso para presentarles la investigación y aclararles alguna duda, pero ella resaltó que de ese modo sería más complicado debido a los horarios y plazos. Por otro lado, me aseguró que los cuestionarios serían respondidos por alumnos de la franja etaria de la investigación. Yo no había previsto esa posibilidad y tampoco era mi deseo. Pensaba, además, en la dificultad de "controlar" nuestro campo de estudio. Estamos mucho más a merced de nuestros informantes de lo que ellos pueden percibir y de lo que a nosotros nos gustaría. Acepté su propuesta a pesar de no considerarla ideal y pensaba en los límites de negociación dentro de una investigación. Contrariamente a la primera escuela en la que había podido rechazar que se me indicaran y sugirieran "buenos" alumnos, por parte de una profesora, por considerar que eso afectaba el desarrollo de la investigación, en esta escuela eso no fue posible. Y aquella interferencia en el primer instituto, en comparación con esta, ya no me pareció tan grave.

Los alumnos tienen media hora de lectura por día. Las clases son de 55 minutos y de ese tiempo, 5 son para lectura Es un momento en el que todos leen y pueden leer lo que desean. Pueden leer en voz alta, pueden leer periódicos, e-books, etc. Además, hay una Comisión de Lectura formada por dos profesores y dos representantes de los alumnos, cuyo objetivo es dinamizar y actualizar la biblioteca. También hacen concursos de lectura en voz alta, en castellano, catalán e inglés. Desenvuelven un proyecto de interpretación lectora llamado "Padrinos de la lectura" que ayuda a los alumnos a leer. Según Mariana, la coordinadora pedagógica, los padres de los alumnos muchas veces leen en su lengua madre. En general los alumnos superan la barrera lingüística, cosa que sus padres no consiguen. Da el ejemplo de un alumno que para ir al hospital con su madre tuvo que escribir la autorización él mismo. 
Número 3, mayo 2014. No 03/05. ISSN: 2014-5993

Esto muchas veces obstaculiza el aprendizaje, ya que muchos padres tienen dificultades en ayudar a sus hijos en los deberes de la escuela.

El Institut d'Educación Secundària Joan Salvat Papasseit, creado en 1979, tiene hoy 216 alumnos de 26 nacionalidades. La escuela se encuentra localizada en Ciutat Vella Barceloneta- y está a una cuadra de la playa. Funciona en un edificio moderno, construido especialmente para la escuela. Los alumnos son de familias de clase media y baja y hay un número elevado de extranjeros. Fue, sin duda, el instituto con el que tuve menos contacto y del que obtuve menos informaciones.

Fui a esta escuela a fines del año lectivo, en junio. Hubo bastante dificultad para combinar una fecha, tanto con la dirección como con la coordinación. La visita fue bien rápida, conversé con el director y con algunos profesores y entregué los cuestionarios para que fueran aplicados en los cursos. No hubo tiempo para ninguna otra negociación acerca de la investigación. Me informaron que entrarían en contacto ni bien estuvieran todos los cuestionarios respondidos para que fuera a buscarlos.

El Institut d'Educación Secundària Lluis Domènech i Montaner queda en la Zona Franca Sants- Monjuic, y fue creado en 1996-1997. El edificio en donde funciona actualmente es más reciente, de 2001, y recuerda un poco los CIEPs (Centro de Integrados de Educación Pública), creados por el antropólogo Darcy Ribeiro en el gobierno de Leonel Brizola, en los años 1980, en Río de Janeiro. El instituto tiene 428 alumnos en ESO o Bachillerato y cerca de 10 nacionalidades diferentes. Son alumnos de clase media y baja, cuyos padres, en muchos casos, están desempleados. Hay un gran número de sudamericanos y su perfil es bastante heterogéneo.

Ese fue el último instituto que visité y el más diferente en términos de localización. La coordinadora fue bastante receptiva a la investigación. Después de muchos contactos por correo electrónico, agendamos una fecha para que fuera a la escuela y aplicara, ese mismo día, los primeros cuestionarios. Antes de presentarme y de explicar lo que estaba haciendo allí, pude entrar a las aulas e observar a los alumnos y profesores. Los profesores fueron muy gentiles y colaboraron no solo en la entrega de los cuestionarios, sino también en la aclaración de dudas a los alumnos.

En las cuatro escuelas los cursos tenían más o menos el mismo número de alumnos, entre 25 y 30. Lo que me llamó la atención fue la diferencia de los barrios, de los edificios y de los alumnos. Los edificios de las escuelas Serrat i Bonastre y Miquel Tarradell son antiguos, con "aire de escuela", en oposición a las escuelas en la Barceloneta y en la Zona Franca. Estas son más modernas, con instalaciones amplias. Ya Papasseit cuenta con un gimnasio pero es la menos cuidada. 
Número 3, mayo 2014. No 03/05. ISSN: 2014-5993

El tema de la seguridad es importante en las escuelas y todas ellas tienen una preocupación a ese respecto. En algunas esto se hizo más evidente. La entrada principal de la escuela de Raval queda abierta y conduce a una puerta de vidrio en la que hay un portero electrónico. En Serrat i Bonastre la entrada principal ya tiene un portero electrónico. La escuela de Barceloneta tiene una especie de garita en la que hay una o dos personas, y también un portón grande, lo que demuestra una mayor preocupación con la seguridad. En todas ellas necesité identificarme antes de entrar. En la escuela de la Zona Franca la entrada estaba abierta y pude ir directamente al mostrador para hablar con la recepcionista que me atendió. En casi todas sentí un clima de movimiento y vida. Había barullo, alumnos bajando las escaleras, conversando. Oí el timbre que avisaba de la "hora del patio" y la correría de los alumnos.

Las cuatro escuelas tienen biblioteca. En las tres primeras la misma se encuentra más presente en la rutina de los estudiantes. En Serrat i Bonastre pude conocerla durante las actividades de Sant Jordi y durante las entrevistas que, en su mayoría, fueron realizadas allí mismo. A pesar de ser un poco oscura y de no permanecer abierta todo el tiempo, es bastante frecuentada. La de la escuela Miquel Tarradell no la conocí. Las entrevistas fueron hechas en una sala destinada por la dirección, pero varios alumnos hablaron de ella. En la escuela Pappasseit, la biblioteca no se estaba usando en ese momento porque estaba pasando por una reorganización. Muchos alumnos no la conocían o solo habían ido una vez. Ya los alumnos de la escuela Domènech citaron varias veces la biblioteca, comentaron que ya habían ido solos o con los profesores, pero tampoco pude conocerla. Las entrevistas, en ese caso, se hicieron en aulas desocupadas.

En la escuela de Raval, cuando fui a conocer la institución y a su coordinadora pedagógica, me presenté, expliqué todo lo referente al cuestionario y lo entregué. La escuela se ocupó de fotocopiarlo y de aplicarlo en los cursos. Cuando ya los tuvieran todos respondidos, me iban a avisar para que fuera a buscarlos y preparara las entrevistas.

\section{Datos del cuestionario.}

Sumando las cuatro escuelas, se aplicaron 248 cuestionarios entre los meses de abril y junio de 2013.

\begin{tabular}{|l|}
\hline $55,3 \%$ Hombres \\
\hline $44,7 \%$ Mujeres \\
\hline
\end{tabular}

Promedio de edad: 14 años (con alumnos entre 10 y 19 años)

\begin{tabular}{|l|}
\hline $78,9 \%$ tienen el hábito de leer \\
\hline $21,1 \%$ no tienen el hábito de leer \\
\hline
\end{tabular}




\section{GRAFO Working Papers}

Número 3, mayo 2014. No 03/05. ISSN: 2014-5993

Frecuencia con la que leen:

\begin{tabular}{|l|}
\hline Muchas veces $40 \%$ \\
\hline Lee todos los días $36 \%$ \\
\hline Una vez a la semana $10 \%$ \\
\hline Una vez al mes $6 \%$ \\
\hline Solo los fines de semana $4 \%$ \\
\hline
\end{tabular}

Gustos:

\begin{tabular}{|l|}
\hline Libros 29\% \\
\hline Web 29\% \\
\hline Revistas 23\% \\
\hline Blogs 6\% \\
\hline Periódicos 5\% \\
\hline Otros 8\% \\
\hline
\end{tabular}

Cómo eligen los libros:

\begin{tabular}{|l|}
\hline $34 \%$ por recomendación de un amigo \\
\hline $20 \%$ Lo ve en la Biblioteca \\
\hline $15 \%$ por recomendación del profesor \\
\hline $15 \%$ Publicidad \\
\hline $13 \%$ TV \\
\hline $3 \%$ Periódicos \\
\hline
\end{tabular}

Bibliotecas en las escuelas:

$76 \%$ de las escuelas tienen bibliotecas

$24 \%$ de las escuelas no tienen biblioteca

Biblioteca del barrio:

\begin{tabular}{|l|}
\hline $94 \%$ conoce la biblioteca de su barrio \\
\hline $6 \%$ no conoce la biblioteca de su barrio \\
\hline
\end{tabular}

Padres lectores:

\begin{tabular}{|l|}
\hline $66,7 \%$ Madres \\
\hline $44,1 \%$ Padres \\
\hline
\end{tabular}

Más del $15 \%$ no supo decir si el padre o la madre son lectores. 
Número 3, mayo 2014. No 03/05. ISSN: 2014-5993

\section{Lengua en la que leen:}

\begin{tabular}{|l|}
\hline $93,2 \%$ español \\
\hline $\mathbf{7 1 , 8} \%$ catalán \\
\hline 34,7 inglés \\
\hline $3,2 \%$ francés \\
\hline $5,2 \%$ otros \\
\hline
\end{tabular}

Haciendo un primer análisis de estos datos, algunos aspectos quedaron en evidencia. Teniendo en cuenta la totalidad de los estudiantes, se observa que hay más hombres que mujeres. La mayoría afirma tener el hábito de leer, sin embargo, esta afirmación debe ser relativizada ya que se encuentran en la escuela y en esta la lectura es una práctica que se exige. La web comparte con los libros el mismo porcentaje de lectura. Para ese punto del cuestionario la pregunta fue genérica puesto que no se apuntó a lo que leían en internet.

La adolescencia es una fase de transición entre la infancia y la edad adulta, es una fase en la que los jóvenes buscan alejarse de los padres y los amigos adquieren gran importancia en sus vidas. Cuando analizamos las respuestas dadas a la pregunta sobre cómo eligen un libro, la recomendación de un amigo aparece en primer lugar con un porcentaje significativo. En segundo lugar se encuentra la biblioteca. La importancia de esta para los adolescentes es evidente. Ya sea que se trate de bibliotecas escolares o públicas, las mismas son, para ellos, un lugar de referencia. Y la pregunta siguiente trae nuevos aspectos. El $76 \%$ de los alumnos afirman que su escuela tiene biblioteca. Estos jóvenes pertenecen a cuatro escuelas y todas ellas tienen biblioteca. Es decir, la respuesta "correcta" sería decir 100\%, sin embargo ese dato me lleva a pensar que en algunas escuelas no se frecuenta o no se hace uso de la biblioteca, o que incluso no se la conoce, y que por eso 245 alumnos afirman que su escuela carece de una. Ya en relación a si conocen la biblioteca del barrio, la respuesta llega a sorprender: un $94 \%$ de jóvenes responde afirmativamente a la pregunta. O sea, la biblioteca del barrio tiene visibilidad, es conocida y es posiblemente frecuentada. Este me parece un dato relevante sobre la ciudad de Barcelona. Nos detendremos en esto con más detenimiento cuando lleguemos a las entrevistas.

Las investigaciones hechas en torno a la lectura en diversos países, y no solo en España y en Brasil, apuntan al hecho de que las mujeres son más lectoras que los hombres. Basta recordar la Inglaterra del siglo XVIII que describió lan Watt (1990:40-41) en su libro The rise to novel, en el que llama la atención al crecimiento del público lector, sobre todo de aquel que lee novelas. Y dentro de ese público, la creciente presencia de las mujeres de las clases media y alta, lo que acabó provocando que la literatura se volviera un entretenimiento 
Número 3, mayo 2014. No 03/05. ISSN: 2014-5993

básicamente femenino. Hasta aquel momento la novela era considerada un género menor. Solo más tarde ganó el privilegio del mercado editorial occidental. Según los estudiantes, las mujeres, de modo general, y sus madres, en particular, son más lectoras que sus padres, habiendo una diferencia de un $20 \%$ entre ambos. Por otro lado, vale destacar que muchos afirmaron no saber si su madre o su padre eran lectores. En las entrevistas volveremos a ese punto, puesto que muchos adolescentes recordaron que, cuando eran niños, sus madres o abuelas les contaban historias.

La mayoría de los adolescentes afirma que el castellano es lengua prioritaria para la lectura, aun siendo el catalán lengua obligatoria en la escuela. Esto podría comprenderse por el hecho de que en las cuatro escuelas hay un número muy alto de extranjeros y que, de estos, hay latinoamericanos que ya hablaban esa lengua antes de establecerse en Barcelona. Este punto también podrá ser mejor evaluado en las entrevistas, ya que estas nos permitirán captar diferencias y sutilezas a la hora de elegir una lengua. Un gran número de estudiantes también afirmó leer en inglés.

\section{Las entrevistas.}

Creo que las entrevistas abiertas hechas en profundidad son una metodología cualitativa fundamental para poder conocer el universo estudiado. En la primera etapa de esta investigación, llevada a cabo en 2012 con adolescentes de Río de Janeiro, las entrevistas fueron básicamente individuales, y la mayoría ocurrió dentro de las escuelas. Me di cuenta de que tal vez esa no era la mejor manera de hacerlos hablar, ya que muchos se inhibían, daban respuestas cortas, incluso monosilábicas -aun habiendo respondido en el cuestionario que les gustaría ser entrevistados. Nunca había investigado sobre adolescentes y noté una diferencia muy grande con relación a mis otras investigaciones con periodistas (1993), intelectuales (2001) y jóvenes universitarios (2007). En estos tres estudios, la mayoría de los entrevistados se encontraba cómoda en ese rol, a pesar de que para varios de ellos era la primera vez. Ellos querían hablar, las conversaciones eran largas, detalladas y en general duraban más de una hora. Con los adolescentes cariocas eso prácticamente no ocurrió. Sé bien que el hecho de que la entrevista se realizara en la escuela pudo haber influenciado e inhibido a los participantes. Por eso en Barcelona decidí entrevistarlos en grupo y creo que fue una buena decisión. Al comienzo se mostraron tímidos pero, en general, las conversaciones fueron estimulantes: Ios alumnos intercambiaban ideas o se ayudaban con el nombre de algún libro. También muchas veces entraban en desacuerdo y eso les exigía que tuvieran que explicar mejor su punto de vista.

Si la investigación en España hubiese sido más larga, de seguro habría sido muy rico poder oírlos fuera del universo escolar, acompañarlos a alguna actividad o entrevistarlos en sus 
Número 3, mayo 2014. No 03/05. ISSN: 2014-5993

propias casas. Pero lamentablemente eso no fue posible no solo por los plazos, sino también porque se trataba de menores de edad.

En la presente investigación la entrevista tuvo un papel fundamental. A diferencia de la entrevista periodística, en esta el investigador no inquiere al entrevistado, no juzga su discurso, sus actitudes, las opciones hechas, sino que escucha. No busca una respuesta verdadera, objetiva. El hecho de que un entrevistado no responda a una pregunta, por ejemplo, puede decir de él mismo y de su visión del mundo, tanto como si la hubiera respondido. Como subraya la antropóloga Michèle Petit (2008: 55), quien oyó a jóvenes franceses acerca de la lectura:

Lo esencial al realizar una entrevista es ser lo más acogedor posible. Las digresiones que no siempre tienen una conexión aparente con el asunto, son, en realidad, asociaciones libres que tienen sentido. A partir de lo que decían nuestros interlocutores, de lo que parecía estar organizando su forma de hablar, improvisábamos preguntas en función de hipótesis que surgían in situ, y en las cuales entraba una dosis de intuición. $Y$ es preferible olvidar temas que se encuentran en la guía inicial de trabajo, a hacer oídos sordos al improviso. Yo siempre dejo de lado la guía de trabajo en el momento de las entrevistas. Si no, no se aprende nada fuera de lo que ya se sabía.

Las entrevistas forman parte de un conjunto de elementos que componen una etnografía. También incluye la observación participante, la producción de un diario de campo y el diálogo con una bibliografía sobre el tema en cuestión. Sin embargo, lo fundamental es tener en cuenta que más que una descripción densa, es un esfuerzo intelectual dirigido al otro. El antropólogo español Ángel Díaz de Rada (del Olmo, 2010: 60) afirma que "la etnografía es una experiencia de traducción entre el mundo social de las personas cuya acción estudiamos y el mundo social de la disciplina antropológica con sus procesos y estructuras de saber experto". Y la idea de traducción atraviesa este trabajo desde el aspecto lingüístico hasta las conclusiones.

Se realizaron 12 entrevistas en grupos de tres a cinco adolescentes. En total fueron 48 estudiantes que pertenecían a las cuatro escuelas. Luego entrevisté de manera individual a cuatro de esos mismos jóvenes. Los estudiantes tenían entre 13 y 18 años, algunos eran españoles y otros pertenecían a otras 14 nacionalidades (Bangladesh, Polonia, Ecuador, Argentina, India, Uruguay, Filipinas, Honduras, Bolivia, República Dominicana, Colombia, Marruecos, Brasil, Chile). Como ya mencioné más arriba, todas las entrevistas fueron realizadas y grabadas dentro de las escuelas, dentro del horario de clase; otras fueron hechas en la biblioteca y otras en salas vacías. 
Número 3, mayo 2014. No 03/05. ISSN: 2014-5993

En algunas escuelas, para seleccionar a los jóvenes que serían entrevistados, tuve que hacer una especie de "sorteo", dado que muchos deseaban participar. En la primera escuela hubo cursos en los que todos querían hablar. Algunos profesores me señalaban o sugerían alumnos considerados "buenos" o lectores. No obstante, les expliqué que la investigación era sobre lectura y que me interesaba mucho oír a los "no lectores". En la medida de lo posible intenté no dejarme influenciar por las sugerencias que me habían hecho. El hecho de que muchos hayan respondido afirmativamente a si deseaban participar de la segunda etapa de la investigación, me parece relevante y señala el deseo de estos jóvenes de hablar y, principalmente, de ser oídos, de que sus respuestas sean tenidas en cuenta.

La lectura para muchos adolescentes está conectada con el universo doméstico, con la intimidad de la casa, sobre todo del cuarto. A la mayoría le gusta leer acostado en la cama antes de dormir. Como cuenta N. 13 años, catalán : "Por la semana leo en la cama a la hora de dormir". Surge la idea de un tiempo y un espacio específico para sumergirse en otro mundo, para alejarse de la cotidianeidad y de los estudios. Otros, al contrario, prefieren leer dentro de algún medio de transporte, tal como comenta A., 14 años, catalán : "Siempre llevo un libro cuando cojo el metro, sino me aburro". Aquí aparece la idea del libro como un compañero que distrae y hace compañía durante el transcurso del viaje. Sin embargo, para L., 14 años, española, el libro puede llegar incluso a "molestar" y hacerle equivocarse de camino: "En el bus, si llevo un libro, me meto en la lectura y cuando miro ya me ha pasado la parada". La conexión con el libro llega a sacarla del mundo real.

Volviendo a la lectura nocturna en el ambiente familiar, creo que este dato remite a la práctica desarrollada por varios padres y abuelos de contarles historias o leerles libros a sus hijos o nietos antes de dormir. Es el caso de G., de 15 años, catalán, que recuerda que cuando era niño: "Mi madre me leía cuentos hasta los cinco años y medio y mi padre nunca me leyó nada. En mi familia la que más lee es mi abuela". Esta experiencia no fue vivida solamente por este adolescente, sino por varios otros que comentaron que su madre, hermana o abuela también les contaban historias. Esos recuerdos forman parte de su infancia y aunque no hayan sido determinantes en su formación lectora, de seguro ejercieron influencia.

El caso de J., de 13 años, catalán, es interesante porque relativiza el papel de los padres. Sus padres son lectores, tienen muchos libros en casa, pero eso no hizo de él un lector. No le gusta leer. Cuando era niño su madre le contaba historias pero hoy él cree que los libros son cada vez más largos y más aburridos. A su padre, lo describe así: "Mi padre tiene eso de leer como una enfermedad, está todo el tiempo con un libro y me obliga a leer pero yo paso de todo". 
Número 3, mayo 2014. No 03/05. ISSN: 2014-5993

En general, y según los testimonios, hay muchas madres lectoras, ya sea que se trate de novelas o revistas. F., de 15 años, es de Bangladesh y cuenta que a sus padres les gusta leer. Su madre prefiere leer libros en Bangladesh porque no entiende mucho el castellano ni el catalán y sale poco de casa. Pero los estudiantes no siempre mencionan a sus padres. Algunos no supieron decir si ellos eran lectores y otros destacaron los periódicos deportivos como su lectura predilecta. Lectores o no, se hace evidente, en el habla de estos jóvenes, que independiente de que sus padres sean profesionales liberales, empleados o desempleados, los padres valoran el estudio y creen que para que sean "alguien" en la vida sus hijos necesitan leer.

Para los entrevistados, frecuentar la biblioteca pública forma parte de su vida cotidiana. Todos tienen carné de biblioteca, conocen bien la biblioteca de su barrio y la frecuentan por motivos diversos: para hacer los deberes, encontrar amigos o retirar un libro. M., de 16 años, española, dice: "Voy a la biblioteca a hacer deberes porque en mi casa no me concentro una vez que hay demasiado ruido y también la tele y el ordenador me entretienen". Aquí se dice que la biblioteca no es solamente un espacio para retirar libros y surge el problema de la concentración, presente en muchos testimonios. Es el problema de concentrarse, de "entrar" en un libro, de prestar atención en la clase. Algo que une a los jóvenes de Río de Janeiro y de Barcelona, y tal vez a los de otras ciudades del planeta. Lo cual se conecta con esta franja etaria, que se caracteriza por ser una fase de transición, de alteraciones del humor y hormonales, de relación intensa con los medios de comunicación y de sentir necesidad de estar siempre conectado.

Por otro lado, la biblioteca aparece también como fuente de información sobre libros. En los cuestionarios muchos afirmaron haber elegido libros que fueron recomendados en la biblioteca. Esta funciona como una vidriera en la que se muestran ofertas variadas, según lo que cuenta $\mathrm{M}^{\circ}, 16$ años, español: "Voy más a la biblioteca para elegir un libro". Lo que le atrae es el tema.

A partir de los testimonios de muchos jóvenes, de mi experiencia de vida en Barcelona, de mi experiencia como usuaria de bibliotecas públicas, de la observación de ese espacio público y de las entrevistas que realicé con especialistas del área, me fue posible entender la dimensión y el significado de la biblioteca pública de Barcelona. Según una información cedida por una entrevistada que pertenece al sector, es el servicio público mejor evaluado en la ciudad. Las bibliotecas son un espacio de información, de recreación, de entretenimiento. Un espacio gratuito de préstamo de libros, CDs y DVDs, un espacio de acceso libre al acervo y a internet, de actividades amenas para niños y culturales para jóvenes y adultos, y que incluso funciona durante la noche y también los sábados. El "carné" de la biblioteca da descuentos en muchas actividades culturales, así como en librerías, y para sacarlo basta con 
Número 3, mayo 2014. No 03/05. ISSN: 2014-5993

presentar un documento de identidad y un comprobante de domicilio. Varias bibliotecas tienen un club de lectura para jóvenes y adultos, además de una estrecha relación con las escuelas del barrio. Además, antes del comienzo del año lectivo tienen la preocupación de conseguir los libros que las escuelas van a adoptar, con el objetivo de que haya ejemplares suficientes para los alumnos. Esto es posible gracias a la red de comunicación que existe entre las bibliotecas, la cual permite que los libros circulen con rapidez.

¿Cuál es la relación de estos jóvenes con la lectura? De ellos, oí frases como estas: "Me gusta leer cuando quiero", "Para mí leer es un placer", "Leer te lleva a mundos inexplicables", "No sé explicarlo muy bien pero es un sentimiento muy guay, bonito", o "Me meto en la lectura, me lo imagino". Estas afirmaciones señalan que a muchos les gusta leer y que dicha experiencia puede ser rica y placentera.

Creo que la idea de experiencia que da título al proyecto de esta investigación, merece que reflexionemos. La obra de Jorge Larrosa (2002; 2003), profesor en el área de Educación de la Universidad de Barcelona sobre la experiencia de la lectura, fue fundamental para el desarrollo de este trabajo. Su punto de partida es Heidegger (1979; 143), quien dice:

Hacer una experiencia con algo -sea una cosa, un ser humano, un dios- significa que nos acaece, nos alcanza; que se apodera de nosotros, que nos tumba y nos transforma. Cuando hablamos de 'hacer' una experiencia, esto no significa precisamente que nosotros la hagamos acaecer; hacer significa aquí: sufrir, padecer, tomar lo que nos alcanza receptivamente, aceptar en la medida en que nos sometemos a ello. Algo se hace, adviene, tiene lugar.

Tal vez esta investigación haya sido guiada por el deseo de descubrir si para estos jóvenes la lectura es una experiencia como lo fue para mí. Tal vez no lo sea para todos ni tampoco siempre. Tal vez lo sea para algunos y en algunos momentos.

Y entender la experiencia como lectura implica pensar en el cómo. En cómo leen y no tanto en qué leen, aunque esto también sea importante. El historiador Carlo Ginzburg (1987) en su obra El queso y los gusanos muestra de qué manera un molinero perseguido por la inquisición, debido a sus ideas, entiende el universo y su historia en función de sus lecturas. Estas influyeron en su visión de mundo dentro de un contexto de amenaza y de terror y van construyendo su identidad. La experiencia de la lectura surge como algo que se apodera de nosotros y nos transforma. Se vuelve un elemento fundamental en la construcción de uno mismo, particularmente en la adolescencia y en la juventud, tal como lo subraya Petit (2008). Siguiendo con el punto sobre cómo leen, yo tenía curiosidad por saber si estos jóvenes leían en otras plataformas, además del libro tradicional, como computadoras, tablets, celulares. Para mi sorpresa, la lectura fuera del libro de papel es pequeña y restricta. Usan mucho la 
Número 3, mayo 2014. No 03/05. ISSN: 2014-5993

computadora, leen textos en internet, entran en blogs, algunos usan mucho el celular pero no para leer libros. A., brasileño, 16 años, afirma: "Me quedo mucho tiempo en el ordenador, pero leo noticias y no libros". Ma., 16 años, catalán, dice: "en la pantalla leo un artículo, no libros", y un tercer joven, B., 18 años, bengalí, completa: Yo tengo un libro en el móvil, de deportes". Por medio de estos testimonios es posible establecer una especie de clasificación de las lecturas con los soportes correspondientes. Volvemos, de esta manera, al trabajo clásico de M. Mauss y de E. Durkheim $(1981 ; 43)$ y a la idea de que clasificar es una necesidad básica del hombre.

Clasificar no es solamente constituir grupos: es disponer estos grupos según relaciones muy especiales. (...) Toda clasificación implica un orden jerárquico del cual ni el mundo sensible ni nuestra conciencia nos ofreció un modelo.

Para estos jóvenes, los soportes no se asocian a los libros, sino que los utilizan para leer textos cortos y específicos. Un artículo, noticias o un libro de deportes con bastante ilustración y poco texto, según la explicación de B. Los tres comentarios anteriores son de muchachos, lo que apunta también a una cuestión de género dentro del grupo en que los hombres tienen una relación más estrecha con la tecnología y, en general, menos cercana, a la literatura. Por ejemplo, cuando Ma., 16 años, catalana, habla sobre leer en un Tablet, dice: "Me gusta tener el libro, pasar las páginas...", mientras que se muestra preocupada por la extensión del libro y el hecho de no poder verlo dentro de una computadora: "No me gusta leer en internet porque me gusta saber el tamaño del libro". Esto puede llevarnos a pensar que es una lectora que no enfrenta grandes libros, sin embargo no parece ser el caso. Incluso porque los grandes best sellers juveniles como Harry Potter, Crepúsculo o El Señor de los Anillos tienen más de 300 páginas y constan de diversos volúmenes.

Para estos adolescentes la lectura no siempre produce una experiencia y, cuando lo hace, esta no siempre es de placer. Los testimonios ayudan a entender cómo se sienten con relación a la lectura: "Cuando leo un libro no entiendo nada", "Me gustaría mucho leer pero no tengo concentración para leer un libro", "Los viejos son más lectores porque tuvieron una educación que los hacía leer más. Hoy tenemos cosas más divertidas por hacer que leer" y "No me gusta leer pero es una cosa muy importante". Esta última declaración toca un punto importante en el contexto estudiantil. Me parece evidente que para todo este universo la lectura es importante. Ninguno de los jóvenes entrevistados dijo que no era relevante o necesaria, sino que por el contrario, lo que surgió en las entrevistas es que la lectura es importante pero no puede ser vivida como una experiencia interesante o placentera.

$Y$ en este punto entra un segundo elemento que ayuda a entender la razón de esa división. Se trata de la obligación. La obligación de leer impuesta por la escuela. Para varios de estos 
Número 3, mayo 2014. No 03/05. ISSN: 2014-5993

jóvenes parece muy difícil disociar la lectura de la escuela o de un acto obligatorio. La obligación surge como un problema, como un elemento que puede hacer que la persona se aleje del libro. Yo conversaba con los jóvenes sobre ese tema como si el mismo fuera exclusivo de la escuela y de la lectura. Al fin de cuentas, la vida está llena de obligaciones. En el trabajo, en casa, en la calle y en la escuela. Son muchas las investigaciones (Dauster: 2010, 2012; Colomer: 2009; Petit: 2008; Cassany: 2009; Lluch: 2010) que enfatizan sobre el "peligro" de que el trabajo en la escuela acabe siendo contraproducente, al hacer que los estudiantes se alejen de la lectura, en vez de hacer que la misma forme parte de sus vidas y se vuelva una actividad de placer. El punto clave sería de qué manera la escuela podría llevar adelante un programa de lectura. Durante la investigación observé que en las escuelas se les exige a los jóvenes que lean de cuatro a seis libros por año, en español, catalán e inglés. De esta manera, la escuela cumple su papel de presentarles la literatura del país, los clásicos, de ampliarles el repertorio literario, así como de abrirles el horizonte hacia la lectura.

Por medio de los testimonios pude darme cuenta de lo tenue que es el límite entre el estímulo a la lectura y el fuerte rechazo hacia los libros, debido a la exigencia de una lectura con reglas específicas. La escuela puede estar corriendo el riesgo de tener estudiantes que solo leen los libros para las pruebas, que se sacrifican para tal, y que mantienen una relación de distanciamiento con esas obras, todo lo cual no estaría contribuyendo en nada a crear "amantes" del libro y de la lectura, sino que, al contrario, estaría generando resistencia y desinterés. Y esto no ayuda a crear un país de lectores. En Brasil, la segunda edición de la investigación Retratos da Leitura (2008) aportó datos importantes y también tristes. El índice de lectura cae vertiginosamente cuando los jóvenes salen de la escuela. El testimonio de un adolescente de Río de Janeiro refleja bien este problema: "Después de que salga de la escuela, no voy a necesitar leer más nada".

En lo que se refiere a la lectura, el término obligación apareció de manera recurrente en mi investigación. En todas las entrevistas, grupales e individuales, el término surgió en asociación con la escuela. Incluso aquellos a los que les gusta leer ya debieron hacerlo por obligación, por exigencia de la escuela. Muchos terminaron de leer la obra exigida y no les gustó. Tampoco comprendieron por qué tuvieron que leerla. Pocos se sorprendieron con esto. Hay muchos textos que parecen estar bien distantes de ellos, que no consiguen establecer un contacto, y en aquellos a los que no les gusta leer, esto solo refuerza la idea de que leer es "aburrido", o de que ellos no tienen capacidad de entender lo que leen o de concentrarse en la lectura.

Pero no todos piensan así. Muchos adolescentes leen y leen mucho. Intensamente. Muchos libros. Releen, se apasionan, se involucran, siguen toda la "cadena" del libro, esto en el caso 
Número 3, mayo 2014. No 03/05. ISSN: 2014-5993

de que el libro haya dado una película, sites, blogs, fansclub reales y virtuales. Son adolescentes con sentimientos, gustos y deseos intensos. En este universo de jóvenes encontré lectores "aficionados", apasionados por libros, y que mantienen una relación muy personal con lo que leen.

La investigadora Ana Margallo (Colomer, 2009: 224) cree que la escuela no debería despreciar tanto los best sellers para adolescentes ni ver a sus lectores, como sucede muchas veces, como meros consumidores indefensos ante al mundo publicitario. Para la autora, es importante analizar "el papel que juegan los best sellers en la formación lectora de los adolescentes". Y va más allá, al llamar la atención al hecho de que las escuelas quieren "evitar que estas lecturas se conviertan en menú único para algunos de nuestros alumnos, parece urgente hacerlas visibles, identificar su presencia en las lecturas adolescentes y comprender sus mecanismos de atracción".

Esta visión de la profesora española se corresponde con la visión de la investigadora brasileña Lucelena Ferreira (Dauster, 2012: 114-115), quien estudió las representaciones y las prácticas de lectura de alumnos de enseñanza media en una escuela pública de Río de Janeiro. Para Ferreira, la noción de utilidad, en el discurso de los estudiantes de dicha investigación, aparece ligada a la lectura de literatura. Para esos alumnos, si al estudiante no le gusta leer aquello que es valorado por la profesora, no se lo considera lector. Es decir, aquí aparece la auto-representación de los jóvenes como lectores y no lectores. Una representación que se define a partir de un valor externo y de una perspectiva que, en muchos casos, deslegitima la elección de los jóvenes.

Es el caso de la lectura de best sellers, tanto en España como en Brasil. Este aspecto no solo puede sobrepasar el tema de la lectura, sino que además puede tener un potencial nefasto, totalmente opuesto al efecto positivo de la lectura como construcción de sí mismo. Puede contribuir a que los jóvenes no consigan afirmar sus opciones, trátese de libros, películas, actitudes $u$ opiniones. Las mismas no son valoradas ni tenidas en cuenta. $\mathrm{Y}$ sus gustos son descalificados. Joëlle Bahloul (2002), en su estudio sociológico sobre los "pocos lectores" y sus lecturas precarias, llama la atención a la noción de lecturas legítimas y a la preocupación con el número de libros que se leen y no, en cambio, con el modo como se leen.

Me acuerdo de una joven de Barcelona, que era lectora, y que en la entrevista grupal quedó inhibida al afirmar que le gustaban los libros para chicas y los best sellers románticos porque sabía que no eran bien vistos. O sea, tenía internalizado un juicio crítico, una especie de "patrulla ideológica" sobre aquello que debe o no leerse. Ella tenía muchas opiniones sobre los libros, conocía bien las historias y sabía por qué la encantaban. 
Número 3, mayo 2014. No 03/05. ISSN: 2014-5993

La tesis de doctorado de Cristina Aliagas sobre el "no lector", dentro de los parámetros escolares, ofrece varios aspectos. En su investigación, la autora acompañó a un adolescente -Arnau- durante aproximadamente dos años, de sus 16 a sus 18 años. Durante ese tiempo, observó la vida del joven, su rutina, sus amigos y conversó con él sobre lectura y sobre la dificultad que tenía con la misma. Aliagas (2009: 98) afirma: "Lo más interesante de su historia lectora es que aunque no lee para la escuela, fuera del sistema educativo ha construido una vida lectora activa y variada, pero de textos que el canon literario no reconoce como legítimos". Creo que Arnau es un ejemplo de joven que es capaz de construir una historia de lectura paralela al modelo escolar de textos clásicos y de "calidad". Aliagas subraya que "algunos no leen literatura ni dentro ni fuera del contexto escolar, pero esto no significa que no lean: leen periódicos, blogs y escritos funcionales de sus colegas, textos sin categoría literaria, alejados del canon literario y de los modelos educativos establecidos, pero que son, nos guste o no, sus textos, los que generan por su cuenta". Y aquí llegamos a un punto fundamental de nuestro recorrido por los adolescentes y la lectura: la motivación, el interés, el gusto por la lectura.

Por lo tanto, el placer de la lectura está muy presente en el universo juvenil. Muchos de estos jóvenes son ávidos lectores, ven en la lectura muchos aspectos positivos y no les parece aburrido leer, al contrario de lo que piensan varios de sus compañeros. Y los gustos varían. A muchos adolescentes les gustan las novelas; a otros les gustan los mangás y a otros, la ciencia ficción, los libros de misterio y de terror. Hablan con bastante facilidad y desenvoltura sobre libros que los marcaron y sobre sus autores predilectos. Usan mucho la expresión "me meto en la lectura". La metáfora de la lectura como viaje aparece frecuentemente. Un ejemplo de esto es la afirmación hecha por una joven: "leyendo viajas sin pagar". Y nuevamente aparece la idea de obligación: "Para mí leer es un placer, no una obligación".

\section{Consideraciones finales.}

Este es un trabajo que aún se encuentra en marcha, un "work in progress", por lo tanto, no puedo todavía hablar de conclusiones más profundas y definitivas. El trabajo de campo acabó pero no, en cambio, la investigación ni el análisis de los innúmeros datos recogidos en las dos ciudades a lo largo de dos años.

Terminada la etapa de las entrevistas, después de un primer análisis del material, entré en contacto con las escuelas -tal había sido mi compromiso- y les presenté los datos obtenidos y los resultados parciales. Todas las escuelas parecian muy interesadas en oírme, en saber lo que tenía para decir, lo que había "descubierto", sin embargo, solamente volví a una de ellas. La idea era presentarles un breve resumen de la investigación a la dirección, a la 
Número 3, mayo 2014. No 03/05. ISSN: 2014-5993

coordinación y a algunos profesores. Como mi estadía en Barcelona tenía una fecha límite, solo tuve hasta comienzos de diciembre para hacer dicha presentación.

Le hice un breve relato de la investigación a la coordinadora del Instituto Domènech $\mathrm{i}$ Montaner, un día en que la escuela estaba bastante atribulada, motivo por el cual no pudieron participar del encuentro ni la directora ni los otros profesores. A ella le comuniqué las conclusiones que presenté aquí de forma preliminar.

Los trabajos sobre lectura, en Brasil, en general son escasos, sobre todo los que parten de una perspectiva antropológica, fruto de etnografías y de estudios de recepción con enfoque en el receptor y en su habla. En mi opinión, algunos aspectos se hicieron muy evidentes durante la observación y la escucha de estos adolescentes. Ellos leen, sí, aunque no como les gustaría a sus padres, a sus profesores y a la sociedad. Leen de distintas maneras y diferentes textos. Tienen una gama de lecturas vasta y mixta: van de los comics a los libros escolares, pasando por blogs, best sellers y clásicos. En general, pude percibir que el libro forma parte de sus vidas.

Las bibliotecas públicas en los barrios tienen un papel fundamental en la ciudad de Barcelona. Son un espacio de estudio, de socialización y de contacto libre y voluntario con el libro, tal como lo demostraron los testimonios dados por los jóvenes. Luego de diversas visitas a distintas bibliotecas, pude ver que los ellos frecuentan más las bibliotecas públicas que las bibliotecas escolares.

Los padres y la familia son muy importantes en la construcción de los jóvenes lectores, pero no son determinantes. Pero es cierto que los adolescentes más lectores crecieron en un ambiente de estímulo a la lectura: sus madres les contaban historias antes de dormir cuando eran niños; sus padres eran lectores, frecuentaban bibliotecas y librerías, compartían lecturas y daban valor al libro. Sin embargo, nada de eso garante que sus hijos serán lectores y eso quedó demostrado en varios testimonios. En las declaraciones dadas también surgió lo contrario, es decir, padres menos lectores, con un bagaje cultural más limitado, con poca intimidad con los libros, pero que de alguna forma le dan valor a la escuela y, sobre todo, al estudio. Estos también ayudaron a crear lectores.

El rol de las escuelas en el proceso de formación de lectores es fundamental y bastante complejo. Es evidente que un ambiente propicio para la lectura con discusión en el aula, con una producción de textos literarios por parte de los alumnos, con participación en fiestas literarias, facilita la "producción" de adolescentes lectores. En este sentido, la escuela tiene por delante el desafío de hacer que la obligación de leer no aleje a los estudiantes del libro, no les impida adquirir el hábito de la lectura ni les impida sentir el placer de leer.

Pedro Cerrillo (Lluch, 2010: 96), al analizar la enseñanza de la literatura y de los clásicos literarios en España, llama la atención sobre la necesidad de que las escuelas recurran "a 
Número 3, mayo 2014. No 03/05. ISSN: 2014-5993

diversas estrategias que hagan más flexible la 'obligatoriedad' de su lectura: la selección rigurosa de los textos (teniendo en cuenta la posible empatía de los mismos con los lectores, la cercanía de sus contenidos o personajes y la accesibilidad de su lenguaje), las adaptaciones y sus lecturas fragmentadas". Es decir, si la escuela no se mantiene atenta al contexto y a los intereses de los jóvenes, de nada servirá exigirles que lean seis libros por año. Una alternativa sería que uno de los libros de lectura obligatoria durante el año lo eligiesen los alumnos, a partir de una discusión en clase, de un debate cuidadoso, con derecho a defender los autores y títulos mediante algún tipo de votación y en el que los alumnos se sientan participantes de ese proceso.

Teresa Colomer (2009: 54) es bastante crítica en relación con la actitud de las escuelas. Para la profesora y estudiosa de literatura infantil, el efecto de la escuela ha sido el de formar y disuadir, ya que el camino que la escuela transita con los alumnos no los lleva a leer permanentemente, sino muchas veces a leer menos. La escuela crea un rechazo y en determinados momentos la presión escolar les impide a los jóvenes que hagan una lectura más personal. La escuela puede y debe ser capaz de crear un espacio literario que permita la concepción de un lector.

En la investigación realizada en las dos ciudades también me di cuenta de que es fundamental que se abra un espacio para que los adolescentes puedan expresarse. Muchos querían ser entrevistados, hablar, contar su historia, su vida, hablar de sus lecturas y de sus dificultades con la misma. No hay duda de que la lectura es para todos ellos un valor, incluso para los no lectores. Nadie negó su importancia y muchos afirmaron que leer era un requisito esencial para tener éxito en la vida. Por otro lado, la lectura en el ambiente escolar continúa siendo vista como una obligación. Creo que lo más importante para la construcción de una juventud lectora es que se encuentre un punto de confluencia entre el deber y el placer.

Recuerdo aquí el testimonio de una joven y entusiasmada lectora de Río de Janeiro que afirmaba: "si a una persona no le gusta leer es porque todavía no encontró su libro". Frase esta repleta de esperanza y con la cual doy cierre al presente artículo.

\section{Bibliografía}

Aliagas, Cristina Marín (2011). El desinterés lector adolescent. Estudi de cas de les practiques i identitats lletrades d'una colla d'amics des de la perspectiva dels Nous Estudis de Literacitat. Barcelona: Universitat Pompeu Fabra. Tesis doctoral.

_ (2009). “'Aunque lea poco, yo sé que soy listo'. Estudio de caso sobre un adolescente que no lee literatura'. Ocnos. Revista de estudios sobre la lectura. $\mathrm{n}^{\circ} 5$, pp. 97-112. 
Número 3, mayo 2014. No 03/05. ISSN: 2014-5993

Bahloul, Joëlle (2002). Lecturas precarias. Estudio sociológico sobre los 'pocos lectores'. México: Fondo de Cultural Económica.

Cassany, Daniel (comp.) (2009). Para ser letrados. Voces y miradas sobre la lectura. Barcelona: Paidós Ibéricas.

Colomer, Teresa (coord.) (2008). Lecturas adolescentes. Barcelona: Editorial Graó.

Dauster, Tania \& Ferreira, Lucelena (orgs.) (2010). Por que ler? Perspectivas culturais do ensino da leitura. Río de Janeiro: Lamparina.

Dauster, Tania; Pereira, Sandra \& Rocha, Gilmar (orgs.) (2012). Etnografia da educação. Río de Janeiro: Lamparina.

Del Olmo, Margarita (2010). Dilemas éticos en antropología. Las entretelas del trabajo de campo etnográfico. Madrid: Editorial Trotta.

Ginzburg, Carlo (1987). O queijo e os vermes: o cotidiano e as ideias de um moleiro perseguido pela Inquisição. São Paulo: Companhia das Letras.

Heidegger, Martin (1979). De camino al habla. Barcelona: Ediciones del Serbal-Guitard.

Larrosa, Jorge (2002). "Notas sobre a experiência e o saber da experiência". Revista Brasileira de Educação, n 19, pp. 20-28.

_ (2003). La experiencia de La lectura - estudios sobre literatura y formación. México: Fondo de Cultura Económica.

Lluch, Gemma (Ed.) (2010). Las lecturas de los jóvenes. Un nuevo lector para un nuevo siglo. Barcelona: Anthropos Editorial.

Parizzi, Francesca (2003). Un segle d'escola a Barcelona. Barcelona: Ediciones Octaedro.

Peroni, Michel (2003). Historias de lectura. Trayectorias de vida y de lectura. México: Fondo de Cultura Económica.

Petit, Michèle (2002) . Éloge de La lecture. La construction de soi. Paris: Belin, 2002.

_ (2008). Os jovens e a leitura. São Paulo: Ed 34.

Poveda, David (coord.) (2003). Entre la diferencia y el conflicto. Miradas etnográficas a la diversidad cultural en la educación. Cuenca: Ediciones de La Universidad de Castilla-La Mancha. 


\section{GRAFO Working Papers}

Número 3, mayo 2014. No 03/05. ISSN: 2014-5993

De Rada, Ángel Díaz (2013). "Etnografía de la escuela más allá de la etnografía y de la escuela. Tensiones disciplinares y aplicabilidad de los saberes etnográficos.". Trabajo presentado en la UAB en mayo de 2013.

Sarland, Charles (2003). La lectura en los jóvenes: cultura y respuesta. México: Fondo de Cultura Económica.

Travancas, Isabel (1993). O mundo dos jornalistas. São Paulo: Summus Editorial.

_(2001). O livro no jornal. São Paulo: Ateliê Editorial.

(2007). Juventude e televisão. Rio de Janeiro: FGV.

Watt, lan (1990). A ascensão do romance. São Paulo: Companhia das Letras.

Woods, Peter (2011). La escuela por dentro. Etnografía en la investigación educativa. Madrid: Ministerio de Educación y Ciencia/ Espasa Libros.

\section{Webgrafía.}

Retratos da Leitura 2008. Documento electrónico: http://www.snel.org.br/wpcontent/uploads/2012/08/pesquisa_habito_de_leitura_2008.pdf [Consultado el 17 de abril de 2014].

Retratos da 2012. Deitura Documento electrónico: http://www.prolivro.org.br/ipl/publier4.0/dados/anexos/2834_10.pdf. [Consultado el 17 de abril de 2014].

Hábitos de lectura 2012. Documento electrónico: http://www.mcu.es/libro/docs/MC/Observatorio/pdf/Habitos_lectura_2012.pdf [Consultado el 17 de abril de 2014]. 